\title{
Review: Sustainability of crossbreeding in developing countries; definitely not like crossing a meadow...
}

\author{
G. Leroy ${ }^{\dagger}$, R. Baumung, P. Boettcher, B. Scherf and I. Hoffmann \\ Food and Agriculture Organization of the United Nations, Animal Production and Health Division, 00153 Rome, Italy
}

(Received 3 June 2015; Accepted 13 August 2015; First published online 27 October 2015)

\begin{abstract}
Crossbreeding, considering either terminal or rotational crossing, synthetic breed creation or breed replacement, is often promoted as an efficient strategy to increase farmers' income through the improvement of productivity of local livestock in developing countries. Sustainability of crossbreeding is however frequently challenged by constraints such as poor adaptation to the local environment or lack of logistic support. In this review, we investigate factors that may influence the long-term success or the failure of crossbreeding programs, based on the scientific literature and country reports submitted for The Second Report on the State of the World's Animal Genetic Resources for Food and Agriculture. Crossbreeding activities vary widely across species and countries. Its sustainability is dependent on different prerequisites such as continual access to adequate breeding stock (especially after the end of externally funded crossbreeding projects), the opportunity of improved livestock to express their genetic potential (e.g. through providing proper inputs) and integration within a reliable market chain. As formal crossbreeding programs are often associated with adoption of other technologies, they can be a catalyst for innovation and development for smallholders. Given the increasing global demand for animal products, as well as the potential environmental consequences of climate change, there is a need for practical research to improve the implementation of long-term crossbreeding programs in developing countries.
\end{abstract}

Keywords: crossbreeding, sustainability, terminal cross, synthetic breed, developing countries

\section{Implications}

During implementation of a crossbreeding strategy, the longterm sustainability of the organizational system behind the crossbreeding scheme has to be considered to the same extent as the potential improvement of productivity on the animal level.

\section{Introduction}

In general, the stimulation of economic sectors directly supporting the poor is the most effective approach for reducing national poverty indices. In many developing countries, the agricultural sector plays this important role, meaning that smallholders should be at the center of the growth process (Food and Agriculture Organization of the United Nations (FAO), 2012). Enhancement of livestock production contributes to the growth of the agricultural sector, and can be achieved, in part, by improving the productivity of individual animals. Genetic selection makes a major contribution to performance improvement (Havenstein et al., 2003). Within-breed selection (i.e. pure breeding) and

${ }^{\dagger}$ E-mail: Gregoire.Leroy@fao.org crossbreeding (using either local or exotic germplasm) constitute the two techniques for genetic improvement. Contrary to pure breeding, crossbreeding does not produce genetic progress by itself (i.e. in the sense that the additive genetic merit of the crossed animals is equal to the mean of the breeds involved), but has different merits such as using the complementarity between traits and heterosis effects.

In developing countries, initiatives have been undertaken since the end of the 19th/beginning 20th century to replace or create new breeds. Success has been highly variable and dependent on local conditions (Madalena et al., 2002). Lack of adaptation of the crossbreds to harsh production environments (i.e. in terms of climate, diseases and feed availability) and low complementary socio-economic support have raised doubts about the sustainability of crossbreeding in some regions or for some breeding systems. On the other hand, when local conditions allow its proper implementation, crossbreeding has induced substantial increases in animal performance, as well as farmer income (Roschinsky et al., 2015).

Given the large gap in performance in production traits between the highly selected breeds of developed countries and local populations from developing countries, crossbreeding seems to be a logical and seductive solution to 
quickly improve the performance of local livestock populations. In that extent, country reports submitted in 2014 as part of the preparation of The Second Report on the State of the World's Animal Genetic Resources for Food and Agriculture (SoW2) provided interesting insight on the way crossbreeding is considered in developing countries (FAO, 2015). On one hand, no genetic evaluation programs are being implemented for the majority of breeds in non-Organization for Economic Cooperation and Development (OECD) countries (Figure 1 and Supplementary Table S1). On the other, these countries reported a greater proportion of breeds with active breeding programs including crossbreeding than OECD countries. This can be interpreted that developing countries tend to rely on crossbreeding to increase animal performance, rather than within-breed improvement. Genetic progress is therefore imported rather than generated domestically. Note that to a lesser extent, crossbreeding may also exist with breeds from tropical environments selected for high production performance. The country reports also implicate indiscriminate crossbreeding as the main cause of genetic erosion, especially in Africa, Asia and the Near East. This combination of responses seems to indicate that crossbreeding is common in non-OECD countries, but not frequently in a formal manner with programs allowing for local selection in either the hybrid population or the breeds upon which the programs are based.

The aim of this review is to appraise the challenges, potential benefits, risks and opportunities related to the sustainability of crossbreeding programs in developing countries. The paper will first focus on existing crossbreeding strategies, their biological and economic impact, and their extent of use across countries. Then we will consider how the environmental and economical context influences the success and failure of a given crossbreeding strategy in relation to production systems.

\section{Crossbreeding systems and their impacts}

\section{Crossbreeding strategies}

Crossbreeding strategies can be basically classified into four different categories (Table 1) that differ according to whether or not the hybrid animals will be used for breeding and the number of pure breeds that perpetually contribute to the breeding
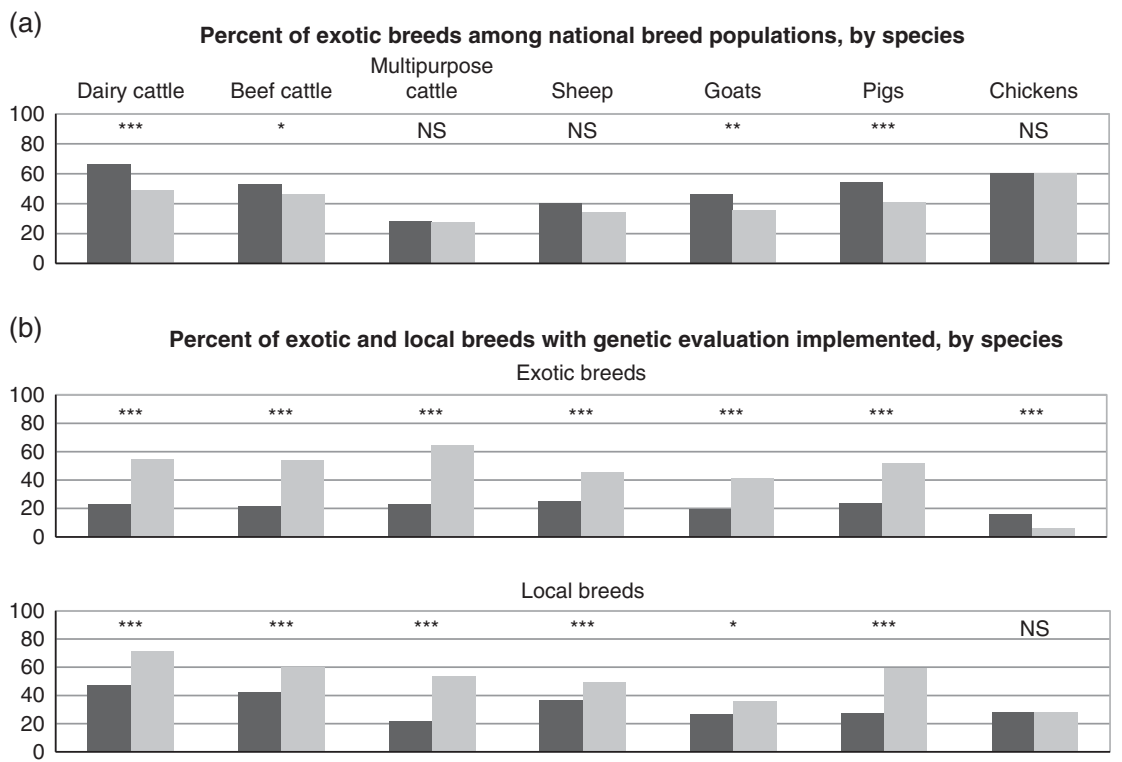

(c) Percent of exotic and local breeds with breeding methods including cross-breeding, by species
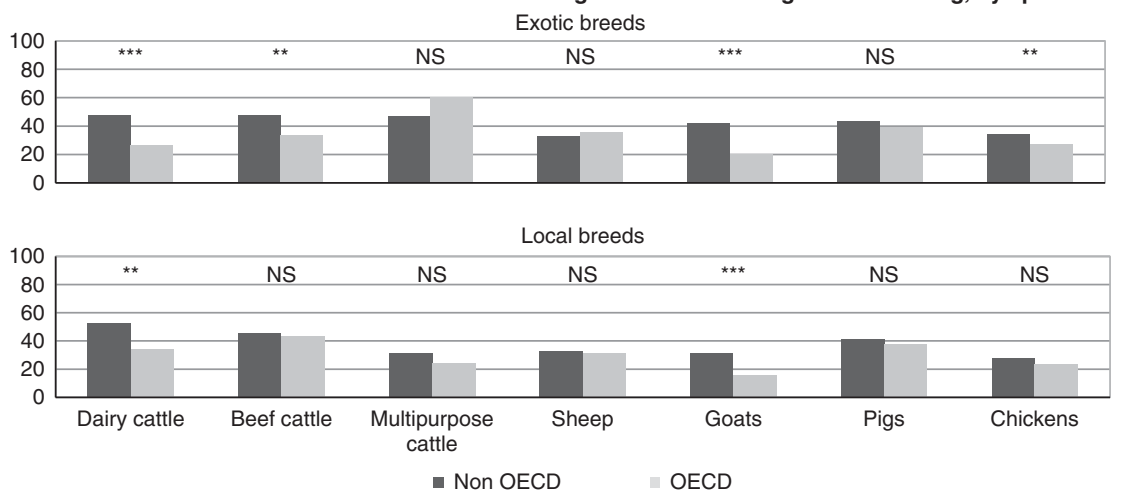

Figure 1 Percent of exotic breeds (a) and percent of breeds reported to be subject to genetic evaluation implementation (b) and to breeding programs applying straight/pure breeding and crossbreeding (c). ${ }^{*} P<0.05,{ }^{* *} P<0.01,{ }^{* * *} P<0.001$ ( $\chi^{2}$ test). OECD $=$ Organization for Economic Cooperation and Development. 
Leroy, Baumung, Boettcher, Scherf and Hoffmann

Table 1 Merits and weakness of various breeding strategies using crossbreeding

\begin{tabular}{lccccc}
\hline \hline Crossbreeding type & $\begin{array}{c}\text { Heterosis } \\
\text { use }\end{array}$ & $\begin{array}{c}\text { Use of adapted } \\
\text { genes }\end{array}$ & $\begin{array}{c}\text { Conservation of } \\
\text { local breeds }\end{array}$ & $\begin{array}{l}\text { Genetic composition } \\
\text { of products }\end{array}$ & Constraints \\
\hline Terminal crossing & Yes & Yes & Yes & Stable & $\begin{array}{c}\text { Need to supply continuously } \\
\text { genetic material (both sexes) } \\
\text { Need to supply continuously } \\
\text { genetic material (males only) }\end{array}$ \\
Rotational crossing & Yes & Yes & Yes & Variable & $\begin{array}{c}\text { Adaptation constraints } \\
\text { Several generations required }\end{array}$ \\
$\begin{array}{l}\text { Breed substitution/upgrading } \\
\text { Synthetic breed creation }\end{array}$ & No & No & Yes & No & $\begin{array}{l}\text { Stable after several generations } \\
\text { Stable after several generations }\end{array}$ \\
\hline \hline
\end{tabular}

program. With terminal crosses, hybrids are marketed. With the other categories, hybrids are reproducers and are subsequently mated with animals from one (breed substitution/upgrading), at least two (rotational crossing) or no (synthetic breed creation) continuously available pure breed(s). Each category has different merits or weakness (Table 1).

The production of terminal F1 crossed individuals constitutes a frequent strategy, considering the use of a female, generally locally adapted and thus endowed with (i.e. naturally selected for) greater fitness (and often maternal abilities), mated with a male, generally exotic and artificially selected for better general production performance. Such a strategy is often applied with the aim of producing animals to be fattened and marketed for meat, although this approach can also be used in dairy systems to produce hybrid females with improved milk production. In a strict terminal cross the offspring of such crosses should not be used for further breeding. Variants may also include a third line in which the female (i.e. the mother of the offspring to be marketed) is an F2 with improved maternal ability.

Rotational crossing is based on the use of crossbred dams that are alternatively mated to different breeds (usually from two to four), with the genetic composition of crossbred dams varying over generations. Similar to terminal crossing, it requires continuous supply of purebred genetic material, but only on the male side, sparing significant cost for breeders, especially in cattle, when a regular source of semen or low-cost males is available. Terminal and rotational crossing aim to optimize the heterozygosity of the product, and therefore the heterosis effect (although heterosis is smaller under rotational crossing). Those two strategies require the management of two (or more) parental lines, with a market chain to provide farmers either purebred reproducers or semen. This need for a continuous germplasm supply represents a major obstacle if infrastructure and logistics are lacking.

The aim of the creation of a synthetic breed is to benefit from the complementary qualities of two or more breeds, for example, adaptation of indigenous breeds, and improved production of exotic ones. In this strategy, crossbreed individuals are used as reproducers and inter se mated over generations. In theory, such programs may include any number of breeds, but two-breed combinations tend to be most common and complexity increases substantially with more than three or four breeds. It requires several generations to have a synthetic breed stabilized, but once the new breed has been provided to farmers, there should be no further need to provide reproducers of the original breeds. The synthetic breed will constitute a new locally adapted breed and ideally will combine the beneficial alleles of the local and exotic breeds. It is important to state that if all farmers adopt the new synthetic breed, such a program may constitute an important threat to local breeds (although the most important alleles from the indigenous populations will presumably be conserved).

Finally, crossing can also be used with the aim of replacing/upgrading a breed. The principle is to backcross hybrid females with males of the exotic breed over a number of generations, increasing subsequently the percentage of genes from exotic origins, until reaching a proportion close to $100 \%$. Such strategies generally imply an even greater threat to local Animal Genetic Resources (AnGRs) than the creation of synthetic breeds, given the fact that indigenous alleles will not likely be conserved, particularly in absence of formal selection programs. Note that breed substitution does not necessarily imply crossbreeding, as indigenous reproducers can also be directly replaced by exotic ones, although this approach is costly owing to the number of females needed.

Although several formal crossbreeding strategies have been well described (Table 1), in practice, crossbreeding is often non-systematic and uncoordinated in developing countries, and as a result, the genetic background of local crossbreeds is often heterogeneous. The studies of Bebe et al. (2003) and Kim and Rothschild (2014) on Kenyan Friesian and crossbreds dairy cattle reported a large diversity of origins (Holstein, Ayrshire, Norwegian Red and Guernsey), even for animals nominally considered to be primarily Holstein.

Performance of crossbred animals under different conditions Multiple studies have investigated the differences in performance level between pure and crossbred animals, considering various environments, strategies, and, of course, breeds and species (Ayalew, 2000; Burrow, 2006; Madalena et al., 2012; Galukande et al., 2013). The outcomes of those studies have generally underlined the following elements:

- Crossbreeding between local and improved genetic resources allows, in a favorable environment, an improvement of performance of production traits such as growth or milk production. For instance, the meta-analysis performed by Galukande et al. (2013) on 23 studies 
comparing local breed (Bos indicus) performance with Bos taurus crossbred animals (under tropics) showed that individuals with $50 \% B$. taurus showed on average 2.6, 2.4 and 2.2 times higher milk yield than local animals in highland, tropical wet and dry, and semi-arid climatic zones, respectively.

- In parallel, fitness traits of crossbred animals are usually deteriorated in comparison with local individuals. For example, a recent study on African Shorthorn Zebu in Kenya linked the level of introgression from European breeds (determined with genome-wide single-nucleotide polymorphism data) to increased vulnerability to infectious diseases (Murray et al., 2013).

- In general, studies have reported greater performance for F1 crosses in comparison with F2, underlining the importance of the global heterosis effect (Madalena et al., 2012; Galukande et al., 2013). In Bangladesh (FA0, 2010a), farmers reportedly interest in the Sonali chicken (Rhode Island Red $\times$ Fayoumi) as subsequent generations could not reproduce the good performance of the F1. The disappointed performance of the advanced intercrosses was cited as one of the reasons for the failure of the Sonali project.

- Genetic $\times$ Environment $(\mathrm{G} \times \mathrm{E})$ interaction is common and consequential, with, as illustrated earlier, a reduction of the relative advantage of crossbreds $v$. local animals relative to production traits in harsh environments. Burrow (2006) indicated that for tropical beef production, in general between $25 \%$ and $75 \%$ of genetic background from the adapted local breed are necessary for optimal beef production, depending on the level of environmental stress. In exceptionally stressful environments, genotypes with $100 \%$ local genetics are optimal.

An important qualifier is that the majority of the studies focused on a limited number of production traits, measured only over short periods of time and usually under experimental conditions, rather than comprehensive in situ studies evaluating lifetime economic returns. The studies also rarely took into account the values of all types of services (traction or manure for instance) provided by the livestock populations (FAO, 2007 and 2014), despite local breeds often highly rated by farmers for those services in comparison with crossbred animals. For example, in Senegal crossbred cattle were rated poorly for traction capacity in comparison with purebred N'dama (Steglich and Peters, 2003). When implementing a given crossbreeding program, it is of paramount importance to consider the consequences on performance not only at the animal level, but also of the farm, including consideration of alternate services, cultural values, and preferences of farmers and consumers. In addition, the impacts on performance and other factors over several generations are rarely addressed and deserve further research.

\section{Economic impacts of crossbreeding}

The potential impacts of crossbreeding may also be considered on levels beyond the farm, such as for the local community or even on national basis. Increased production and commercialization of agricultural activities is likely to contribute to economic growth of developing countries, especially for milk and meat, given their increasing demand. The economic profitability differs between dairy systems, with their continuous flow of income, and meat systems, with irregular sales. In East Africa, national economic development goals have led the dairy industry (including smallholders) to rely more on crossbreds and improved dairy cattle to increase milk production (Makoni et al., 2013). In Kenya, Karugia et al. (2001) estimated that dairy cattle crossbreeding programs had a positive impact on the national economy, increasing social welfare by Ksh. 2.883 billion in 1996 (around \$36 million). However, the same authors also underlined that their analysis ignored some societal cost components of crossbreeding programs, such as the enormous costs in the development and maintenance of these technologies (among other things such as research infrastructure, extension services, mitigation of loss of tolerance to diseases), which may drastically reduce the net societal benefits. According to the same study (Karugia et al., 2001), economic performance on the farm level appeared little improved by the introduction of exotic genes, and the authors speculated that a scenario considering a genetic improvement of local Zebu scenarios may yield the best farm-level performance. In Ethiopia, a recent survey of Roschinsky et al. (2015) showed that depending on the context, income improvement could be the main motivation for dairy cattle smallholders to adopt and maintain crossbreeding.

Yet, the analysis performed by Ayalew et al. (2003) on economic efficiency of Ethiopian goat flocks showed that improved net benefits were primarily related to better management practices rather than to possession of crossbred animals. For meat production, a case study on crossbreeding of Ongole and Simmental in Java showed that the farming system did not change. Although meat production at farm and national levels increased with crossbreeding, farmer income generation was negatively affected and environmental performance not improved (Widi, 2015).

For proper consideration of economic issues, it appears important to differentiate resource-driven systems (i.e. subsidence production systems limited by global input) from demand-driven ones (systems in which production can be adapted to fulfill the demand through output increase and technological improvement). As an example, in Vietnam, Lemke et al. (2007) indicated that the use of improved crossed genotypes allowed for increased revenue, but demanded resources that could not be sustained in resource-driven pig systems.

From a general point of view, efficiency of a given genotype largely depends on production and environmental circumstances such as feed and veterinary costs (Kahi et al., 1998). Therefore, the general recommendation is the use of indigenous livestock in resource-driven systems and of improved animals (crossbred or exotic) in demand-driven systems (Lemke et al., 2007). 


\section{Evidence of crossbreeding in developing countries}

Given the diversity of programs implemented by governments, donors, non-governmental organizations, entrepreneurs and individual farmers over the last 100 years, and the fact that pedigrees are rarely recorded by smallholders of developing countries, it is neither simple to measure the extent of crossbreeding nor to differentiate the amount of crossbreeding through planned strategies from that resulting from unmanaged introgression.

The presence of exotic breeds within countries (Figure 1) may provide a first insight on the extent of breed replacement, albeit without indicating its quantitative importance. When available, national statistics and censuses provide more precise information on the importance of crossbreeding among populations. Table 2 provides examples reported in some countries for cattle, goats, sheep, pigs and chickens; illustrating the variation in crossbreeding across species and countries. According to FAO (2005), locally adapted breeds correspond to breeds which have been in the country for a sufficient time to be genetically adapted to one or more of traditional production systems or environments in the country. Examples of such breeds include Criollo sheep and cattle populations in Peru (Instituto Nacional de Estadistica e Informatica (INEI), 2012). Censuses rarely distinguish between exotic and crossbred individuals, referred in the table as 'improved livestock,' and when the distinction is made, there is in general no differentiation between synthetic lines, F1 or indeterminate crossbred animals. In censuses undertaken in African countries, exotic cattle will usually correspond to European $B$. taurus, even if crossbreeding may also occur between African breeds and tropically adapted breeds recently imported from Brazil (FAO, 2015).

Within cattle, crossbreeding and breed replacement is more frequent for dairy than for beef production. For instance in Kenya, 20\% of cattle have been reported to be of 'improved' type (Minister of State for Planning (MSP), 2009). For dairy animals, the proportion has been estimated around 38\% (FAO, 2011). Similarly, the degree of crossbreds/exotic cattle reported in Uganda in 2009 (6.4\%) included a much larger proportion of individuals for dairy $(5.6 \%)$ than for beef $(0.8 \%)$. It is difficult to state if the share of crossbred animals in the total population is increasing over time. On the one hand, results presented in Table 2 for Eastern and Southern Africa do not basically differ from estimates based on 1990s data (Muriuki and Thorpe, 2002). On the other, in Brazil some surveys indicated a trend toward an increase of the proportion of $B$. taurus origins among dairy farms between 2005 and 2009 (Madalena et al., 2012), whereas in India, the proportions of exotics/crossbreds within national populations in pig and cattle have increased from $7 \%$ to $21 \%$ and $14 \%$ to $24 \%$ between 1992 and 2012 , respectively (Gol/MoA, 1997 and 2012). Note that by contrast, this proportion has remained almost stable for sheep in the same period, increasing from $5 \%$ to $6 \%$. Several hypotheses could be advanced to explain the less frequent use of crossbreeding in small ruminants in comparison with other species. These include a greater prevalence of extensive production
Table 2 Composition of livestock in various countries and species in term of proportions of improved (crossbred or exotic) ${ }^{1}$ and locally adapted breed types

\begin{tabular}{|c|c|c|c|c|}
\hline \multirow{3}{*}{$\begin{array}{l}\text { Species and } \\
\text { countries }\end{array}$} & \multicolumn{2}{|c|}{ Breed type (\%) } & \multirow{3}{*}{$\begin{array}{c}\text { Locally } \\
\text { adapted }\end{array}$} & \multirow[b]{3}{*}{ References $^{2}$} \\
\hline & \multicolumn{2}{|c|}{ Improved } & & \\
\hline & Crossbred & Exotic & & \\
\hline \multicolumn{5}{|l|}{ Cattle } \\
\hline Burkina Faso & \multicolumn{2}{|l|}{0.6} & 99.4 & RGA (2008) \\
\hline Ethiopia & 0.7 & 0.1 & 99.2 & CSA (2010) \\
\hline India & \multicolumn{2}{|l|}{24} & 76 & Gol/MoA (2012) \\
\hline Kenya & \multicolumn{2}{|l|}{20} & 80 & MSP (2009) \\
\hline Nepal & \multicolumn{2}{|l|}{3.4} & 96.6 & CBS (2013) \\
\hline Peru & \multicolumn{2}{|l|}{35.9} & 64.1 & INEI (2012) \\
\hline Uganda & \multicolumn{2}{|l|}{6.4} & 93.6 & UBOS (2009) \\
\hline \multicolumn{5}{|l|}{ Dairy cattle } \\
\hline Brazil & 74 & 6 & 20 & Vilela (2003) \\
\hline Rwanda & 20 & 8 & 72 & Makoni et al. (2013) \\
\hline \multicolumn{5}{|l|}{ Goat } \\
\hline Burkina Faso & \multicolumn{2}{|l|}{0.4} & 99.6 & RGA (2008) \\
\hline Kenya & \multicolumn{2}{|l|}{1} & 99 & FAO (2011) \\
\hline Nepal & \multicolumn{2}{|l|}{2.7} & 97.3 & CBS (2013) \\
\hline \multicolumn{5}{|l|}{ Sheep } \\
\hline Burkina Faso & \multicolumn{2}{|l|}{0.9} & 99.1 & RGA (2008) \\
\hline India & \multicolumn{2}{|l|}{6} & 94 & Gol/MoA (2012) \\
\hline Nepal & \multicolumn{2}{|l|}{0.3} & 99.7 & CBS (2013) \\
\hline Peru & \multicolumn{2}{|l|}{18.9} & 81.1 & INEI (2012) \\
\hline Uganda & \multicolumn{2}{|l|}{0.5} & 99.5 & UBOS (2009) \\
\hline \multicolumn{5}{|l|}{ Pig } \\
\hline Burkina Faso & \multicolumn{2}{|l|}{0.2} & 99.8 & RGA (2008) \\
\hline India & \multicolumn{2}{|l|}{21} & 79 & Gol/MoA (2012) \\
\hline Nepal & \multicolumn{2}{|l|}{7.3} & 92.7 & CBS (2013) \\
\hline Peru & \multicolumn{2}{|l|}{32.8} & 67.2 & INEI (2012) \\
\hline \multicolumn{5}{|l|}{ Chicken } \\
\hline Burkina Faso & \multicolumn{2}{|l|}{0.2} & 99.8 & RGA (2008) \\
\hline Ethiopia & 0.6 & 2.8 & 96.6 & CSA (2010) \\
\hline Kenya & 1.3 & & 98.7 & MSP (2009) \\
\hline Nepal & 42.5 & & 57.5 & CBS (2013) \\
\hline
\end{tabular}

${ }^{1}$ Locally adapted: populations which have been in the country for a sufficient time to be genetically adapted to one or more of traditional production systems or environments in the country. Improved: populations either from exotic origins or that have been subjected to crossbreeding.

${ }^{2}$ See Supplementary Material S1.

systems that typically have more environmental constraints, less use of artificial insemination (Al) and availability of frozen semen, and less sophisticated selection programs for the exotic breeds available for import.

In some cases, local populations have been largely (if not completely) replaced by exotic breeds and crossbred animals. For example, Pattison et al. (2007) reported a gradual replacement of the Pelon pig in Yukatan and estimated that purebred local pigs, crossbred and imported individuals represented $0.3 \%, 45.5 \%$ and $54.2 \%$ of the total population, respectively.

Within crossbred populations, systematic terminal crossbreeding is rarely implemented in cattle. For instance, surveys in Brazil indicated that dairy farmers keep the herd genetic composition intermediate between $B$. taurus and $B$. indicus by 
Table 3 Reasons for success or failure of some examples of crossbreeding programs in developing countries

\begin{tabular}{|c|c|c|c|c|}
\hline $\begin{array}{l}\text { Crossbreeding type and } \\
\text { species (breed) }\end{array}$ & Country & Success & Reason & References $^{1}$ \\
\hline \multicolumn{5}{|l|}{ Terminal crossing } \\
\hline Pig & Vietnam & Yes & Market-oriented production system & Roessler et al. (2009) \\
\hline Goat & Ethiopia & No & $\begin{array}{l}\text { No superiority of crossbred toward indigenous animals } \\
\text { Inability to supply improved stock }\end{array}$ & $\begin{array}{l}\text { Ayalew (2000) } \\
\text { Ayalew et al. (2003) }\end{array}$ \\
\hline Chicken (Sonali) & Bangladesh & No & $\begin{array}{l}\text { Inability to supply improved stock } \\
\text { Following generations unable to reproduce } \\
\text { performance level of F1 }\end{array}$ & FAO (2010a) \\
\hline \multicolumn{5}{|l|}{ Rotational crossing } \\
\hline $\begin{array}{l}\text { Cattle (mostly Holstein/Gir) } \\
\text { Synthetic breed }\end{array}$ & Brazil & Yes & Increased profit & Madalena et al. (2012) \\
\hline Chicken (Kuroiler) & India & Yes & $\begin{array}{l}\text { Improved performance } \\
\text { Integrated distribution channel of 3-week chicks } \\
\text { vaccinated }\end{array}$ & Ahuja et al. (2008) \\
\hline $\begin{array}{l}\text { Cattle (Mpwapwa) } \\
\text { Breed substitution }\end{array}$ & Tanzania & No & Lack of interest from local farmers & Wilson (2009) \\
\hline Cattle (Holstein) & Kenya & Yes & $\begin{array}{l}\text { Zero or semi-zero grazing systems } \\
\text { High potential agroecological area } \\
\text { Market linkage }\end{array}$ & $\begin{array}{l}\text { Bebe et al. (2003), } \\
\text { Otieno (2013) }\end{array}$ \\
\hline Cattle (Holstein) & Ghana & No & Increased mortality due to a low adaptation & Aboagye (2002) \\
\hline
\end{tabular}

${ }^{1}$ See Supplementary Material S1.

changing the bull type more or less regularly (Madalena et al., 2012), with dams being chosen among female calves born within the farm. This informal rotational crossing is of large interest to farmers, as it allows them to spare the cost of buying new female reproducers. By contrast, 'improved' chicken and pigs are nearly always raised in industrial production systems. For instance, animals from commercial broiler and layer lines represent $>95 \%$ of improved animals and around $40 \%$ all chickens raised in Nepal (Central Bureau of Statistics (CBS), 2013). In these cases, systematic terminal crossing is probably widely used, as the high reproduction rates of monogastrics and the low cost of individual animals allow an easy integration of terminal crossbreeding schemes in industrial systems.

Molecular approaches may also provide valuable information on the level of crossbreeding with local populations. In Kenya, Murray et al. (2013) performed genomic analysis on a sample of 500 East African Shorthorn Zebu and reported average introgression levels around $2 \%$, with $20 \%$ of calves showing levels of introgression consistent with crossing with European breeds $\leqslant 5$ generations ago. A study of the same data revealed a greater rate of European introgression in closer proximity to animal markets (Mbole-Kariuki et al., 2014). A study of African village chickens from multiple locations (Leroy et al., 2012) reported evidence of introgression in some of the countries, including Morocco and Cameroon, whereas finding negligible gene flow in some other countries such as Benin or Ghana.

Country reports provided for SoW2 (FAO, 2015) provide interesting information on the source of semen used depending on the context. Figure 2 summarizes the extent of Al (using semen from exotic and/or locally adapted breeds) and/or natural mating according to countries (OECD v. non-OECD), production systems and species. Note this information provides only indirect results on the extent of crossbreeding, as (i) it does not provide information on the genetic origin of female reproducers and (ii) natural mating does not differentiate between sires from locally adapted and exotic breeds. In agreement, with results presented above, Al and exotic germplasm appear more widely used in cattle (and especially in dairy cattle) than in the other species, particularly goats and sheep. Al is reported to be more widely used in OECD countries, whereas the use of semen from exotic breeds is similar between OECD and non-OECD countries. Finally, countries reported more intensive use of $\mathrm{Al}$ and semen from exotic breeds in demand-driven systems (small-scale urban or peri-urban and industrial systems).

In conclusion, the extent of crossbreeding ranges from non-existent to widespread depending on the region, species and production system. In developing countries, crossbreeding seems to be rarely applied in a programmed manner. In industrial production systems, crossbred animals are common, but in that case, coexistence with more extensive systems may also involve risks of introgression into indigenous populations, and subsequent erosion of local genetic resources (Hoffmann, 2009).

\section{Socio-economic and technical factors around crossbreeding based on previous experience}

\section{Factors of success}

In recent history, various circumstances have contributed to the success or failure of crossbreeding programs (Table 3). Generally, most of the external reasons for the sustainability of a crossbreeding program can be linked to one or all of three interdependent factors, namely, the access to adequate 


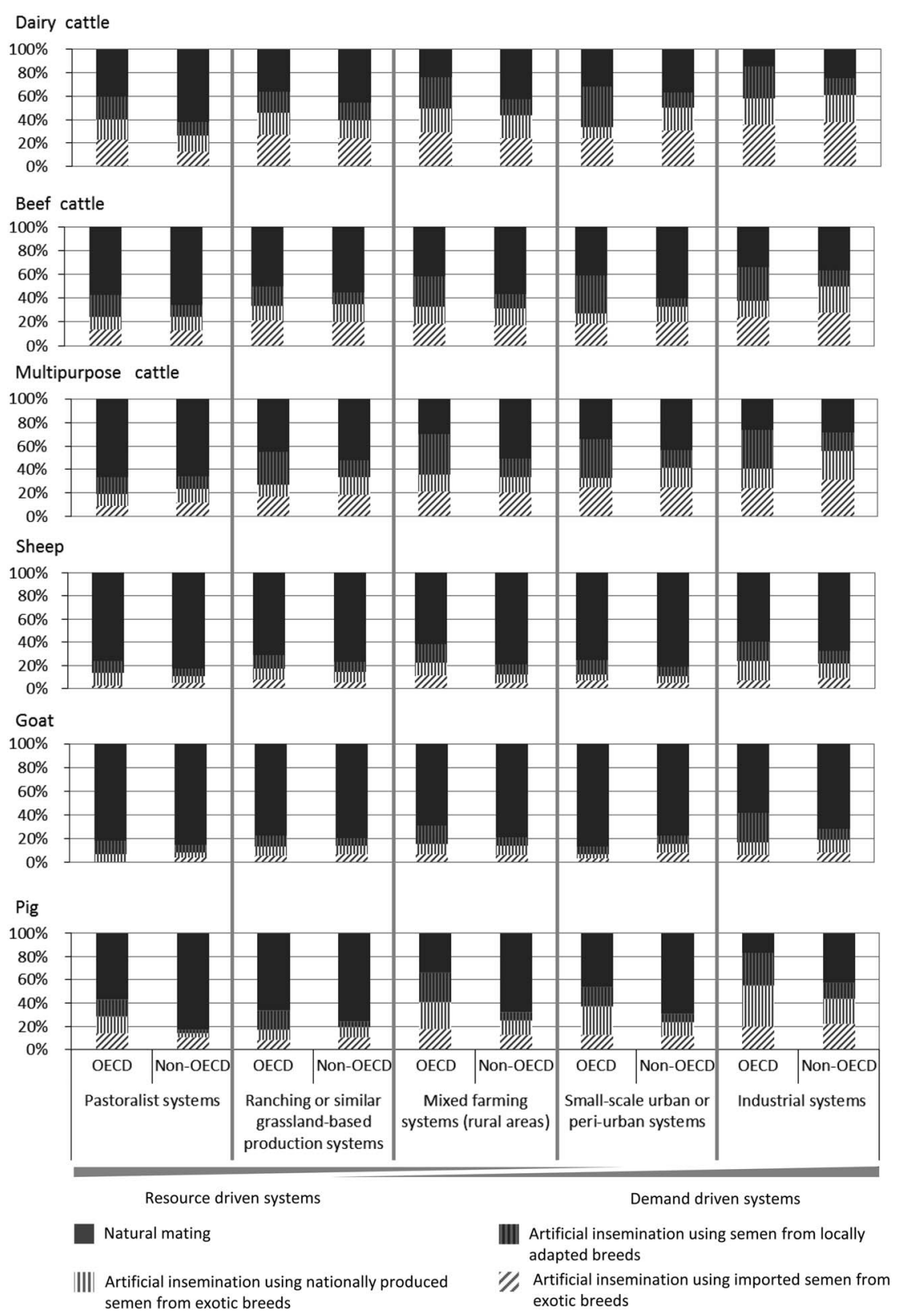

Figure 2 Extent of the use of artificial insemination (using semen from exotic and/or locally adapted breeds) and/or natural mating according to production systems and species in Organization for Economic Cooperation and Development (OECD) and non-OECD countries, based The Second Report on the State of the World's Animal Genetic Resources for Food and Agriculture. The figures are based on relative average scores provided for each reproduction and mating systems: (0) none; (1) low - approximately <33\% of matings; (2) medium - approximately $33 \%$ to $66 \%$ of matings; (3) high approximately $>67 \%$ of matings; or 'production system not present in this country.' Countries where a given species $\times$ production system combinations does not exist were excluded from the calculation of the respective average score.

stock, the opportunity of improved livestock to express its genetic potential and the efficiency of the market chain. The first prerequisite for the success of a given crossbreed program is that performance of crossbred animals must match farmer expectations, which helps ensure that smallholders have the motivation to implement or maintain crossbreeding within their farm (Quddus, 2012; Roschinsky et al., 2015).

\section{Access to adequate stock}

As underlined in Table 1, most crossbreeding strategies require a more or less continuous supply of exotic genetic material. The inability to provide an adequate source of material has been the limiting factor for many failed multiple crossbreeding programs (Table 3). Crossbreeding has frequently been introduced through projects of limited duration, with the assumption that at local stakeholders would eventually take up this responsibility. Although successful in the introduction of crossbreeding, many of these programs have collapsed once the project ended and the costs of genetic material and of breeding/Al center maintenance were no longer supported externally and this responsibility was not taken up by farmers, government or any other stakeholders. This situation occurred for the Bangladesh Sonali chicken improvement program (FAO, 2010a), as the remaining 
logistic structure was not able to ensure the continuous multiplication needed to provide hybrid chickens to smallholders. As recounted previously, farmers were not satisfied with the productivity of the advanced intercross, and thus were not motivated to support the system for their generation. Similarly, after the end of the Ethiopian Dairy Goat Development Program, the institution in charge of the crossbreeding station decreased the number of crossbred animals produced, whereas the few produced (and already purchased) animals were not delivered to the farmers (Ayalew, 2000). More recently, the FARM Africa goat project in Kenya encountered difficulties to identify a private structure willing to produce improved goats, even though the breeding stations already involved could not meet the growing demand for improved goats (Peacock et al., 2011). In those examples, the institutional background and economic incentives merited deserved more investigation and planning before the project started to ensure the supply in the long run. By contrast, one reason for the sustainability of the Kuroiler chicken system in India is related to the fact that chickens are raised until 2 to 4 weeks and vaccinated before selling them to village households. The primary objective of this initial step is to avoid increased juvenile mortality, but it has created a niche opportunity for local entrepreneurs wishing to exploit the demand by farmers for healthy, highly productive birds (Ahuja et al., 2008).

For large species and especially in cattle, access to $\mathrm{Al}$ is a key factor for implementation of crossbreeding, as smallholders do not always have male reproducers. In the study of Miazi et al. (2007) in Bangladesh, crossbred animals were available only in close proximity to Al centers. In their study on dairy cattle in Kenya, Bebe et al. (2003) also showed that farmers owning European $B$. taurus breeds were more dependent on Al than the ones using $B$. indicus. In a smallholder backyard pig production system in India, Kardivel et al. (2013) showed that a crossbreeding with Al delivered in a participatory manner (i.e. with the involvement of village leaders and self-help groups in the Al delivery mechanism) allowed for a significant increase in income for farmers, including savings in mating and female transport cost. The sustainability of this scheme is, however, highly dependent on the institute providing boar semen.

The questions of how the cost of stock provision (Al or reproducers) and maintenance of breeding centers can be covered (i.e. by farmers, breeding organization and/or government) in the long run are rarely assessed in projects involving crossbreeding, even though they are critical for sustainability. Implementation of Al also relies on the farmers ability to detect heat, which may require specific training. Crossbreeding projects should therefore always plan, from the beginning, the sustainability of genetic material delivery and farmer support, which includes determining the cost recovery of those services.

\section{Opportunity for improved livestock to express its genetic potential}

In relation to their higher productivity and generally lower fitness and hardiness, crossbred and exotic animals are likely to be more sensitive to environmental constraints and require more input (i.e. feed and veterinary care) than locally adapted animals. Access to veterinary services, not only physical but also financial, is therefore usually necessary to maintain the good health and productivity of crossbred animals. Crossbreeding programs induce therefore increased costs in terms of management, in particular veterinary support (Karugia et al., 2001; Nath et al., 2013). Such costs are often greater in remote areas. Working with Vietnamese pigs, Lemke et al. (2007) showed that the cost of veterinary treatments increased in households distant from town, reflecting higher transport costs.

Different studies considering adoption of crossbreeding have indeed shown that in harsh conditions, farmers tend to keep more frequently locally adapted breeds because of their greater hardiness relative to crossbred or exotic animals. For instance, in the study of Bebe et al. (2003) on Kenyan dairy farms, the majority of Zebu breeders were in grazing systems $(52 \%)$ and medium potential agroecological zones $(72 \%)$, whereas farmers using European taurine breeds were more frequently in semi-zero or zero grazing systems ( $85 \%$ to $86 \%$ depending on the breed) and in high potential agroecological zones $(71 \%$ to $80 \%)$.

Absolute feed costs per animal are expected to be greater for crossbred animals than for animals of local populations (Nath et al., 2013; Widi, 2015). The reasons for this increased cost include a generally larger body size, resulting in higher maintenance, and the additional demand associated with increased production. In addition, improved animals tend to demand diets with a greater proportion of high quality, more expensive feeds. Although Kuroiler chicken is considered a scavenging/ semi-scavenging bird, it cannot actually meet its food requirement exclusively through scavenging, and therefore requires supplementary feeding (Ahuja et al., 2008). A global assessment found that, while diets of local dairy cows and buffaloes in developing countries usually consist predominantly of roughage $(80 \%$ and $90 \%$, respectively), improved breeds of the two species receive more concentrates and compound feed (FAO, IDF and IFCN, 2014). One of the reasons why the production of crossbred animals has been occasionally reported to be lower than expected is that those animals have not been offered the possibility to express their genetic production potential. For instance, Hassen et al. (2002) reported that crossbred lambs did not perform better than Ethiopian indigenous lambs in daily gain, probably owing to the fact that dams were unable to produce enough milk to fulfill the growth potential of F1 lambs, either because of insufficient nutrition or low genetic capacity for milk production. Availability or cost related to increased feeding is therefore a major factor limiting the interest of using improved animals, especially in resourcedriven systems.

The ability to pay the increased input costs for acquisition and keeping of crossbred animals is clearly related to the availability of capital. In a recent survey of Bangladeshi dairy farmers, three of the four most commonly cited reasons for not adopting crossbred cattle (1. high costs of inputs, 2. high 
price of feeding and 3. lack of money for purchasing animals) involved the economic capacity to purchase inputs. The fourth reason was the complexity of management and the additional investment in time (Quddus, 2012). Other smallholder survey in Ethiopia and Tanzania also showed that availability of capital and access to credit facilitate the implementation of crossbreeding (Abdulai and Huffman, 2005; Mekonnen et al., 2010) by smallholders.

Proper management of crossbred animals also requires greater investment in human capital (e.g. Quddus, 2012). Given the technical skills requirements and management constraints subsequent to the adoption of improved genotypes, there is a need for informing, training and providing support to farmers on the use of crossbreed animals. Therefore, existence of extension services can be considered as a major determinant of crossbred animal adoption, as well as sustainability in the long run (Abdulai and Huffman, 2005; Mekonnen et al., 2010).

\section{Efficiency of the market chain}

As stated earlier, crossbreeding generally increases dependency on farm external input (feed, drugs, improved stock) and technical support (Roschinsky et al., 2015). The question of how smallholders can obtain those inputs, as well how their outputs are commercialized, must be adequately addressed to ensure the sustainability of any crossbreeding program.

Owing to unstable input supply and uncoordinated government extension, Ethiopian dairy farmers had to fill this gap by using their existing resources (Roschinsky et al., 2015). As a consequence, mating to local bulls was undertaken on an emergency basis, meaning that the farmers were unable to follow the originally planned breeding strategy. For pig breeding in North Vietnam, Herold et al. (2010) proposed to improve the existing unsystematic crossbreeding scheme through a stratified scheme, involving indigenous robust Ban and prolific Mong Cai breeds, as well as Yorkshire sires, linked to a marketing program. The new crossbreeding scheme was unable to allow breeders to be independent in terms of breeding stock supply, however. Although Mong Cai breeders could obtain good prices for sows, this income did not compensate for the low prices obtained for purebred Mong Cai finishers (FAO, 2015). On the other hand, the commercialization of purebred Ban products through a short supply chain was proven to be successful, allowing also the maintenance of a pool of reproducers for smallholders practicing crossbreeding.

Before implementing a given crossbreeding strategy, it is recommended to ensure that there are market signals, such as price rewards, to provide incentives for breeders to increase the quality or quantity of their production (FAO, 2010b). One of the main issues to be considered is the lack of transparency in the price transmission through the various stages of the livestock value chain in many developing countries. The multiplicity of actors (e.g. producers, small and large traders, brokers, transporters), as well as lack of objective standards for selling and buying animals (Kocho et al., 2011) lower the ability of farmers to capture the economic benefits from crossbreeding. In this context, standardization of marketing procedures could constitute a clear improvement for smallholders. Otieno (2013) showed that the opportunity for direct sale of animals to the abattoir was a promoting factor of crossbreeding adoption, because abattoir operators were more likely to offer prices based on objective factors such as live weight, whereas in open-air markets, 'eye-ball' remained a frequent basis for assessing the value of animals. Linkage to the market is another important point to consider, and in Tanzania and Ethiopia the proximity to local markets favored the adoption of 'crossbreeding technology' (Abdulai and Huffman, 2005; Mekonnen et al., 2010). In the absence of direct market linkages, the opportunity to differentiate the market and provide products adapted to consumer tastes is often missed (Herold et al., 2010). For instance, in Northern Vietnam, depending on consumers, either lean pork (i.e. from exotic breed pigs) or pork with local flavor/taste (i.e. from local pigs) are preferred (Lapar et al., 2010). Only the producers in a short market chain can exploit these differences in consumer preference.

These three different factors (access to breeding stock, opportunity to express the genetic potential and efficiency of the market chain) are all interdependent because they require coordination to ensure the provision of breeding stock and inputs as well as the connection to the market. Therefore, in absence of a formal organization in support of these three factors, the long-term stability of the crossbreeding system will be compromised. Strengthening of local and regional producer organizations is therefore often considered as the best solution for small-scale producers to deal with the challenges associated with market chains, such as the access to credit and other inputs and output markets (Rege et al., 2011). By organizing themselves, smallholders may increase their competitiveness by, for instance, standardizing marketing price and providing alternative sources of breeding stock. Although horizontal integration may benefit smallholders, vertical integration, either top-down (companies owning farms) or bottom-up (farmers controlling steps of production) may also be an interesting strategy to address the input/output issues (Herold et al., 2012). The Kuroiler example stated above constitutes one example of such vertical integration, where a private company provides 3-week-old vaccinated chickens to smallholders through the intermediate of mother units run by local entrepreneurs.

The establishment of marketing groups or cooperatives linking producers to retail market actors could improve marketing efficacy and profitability of smallholders, and offer the possibility to develop market niches, differentiated for local, crossed or exotic animal products (Kocho et al., 2011). In terminal crossing programs, integration can provide the opportunity to organize stratified breeding schemes, including price transmission between exotic/F1/local stock producers, on a sustainable basis. This corresponds to the system proposed for pig production in North Vietnam described above (Herold et al., 2010; FAO, 2015), which included the establishment of a short food supply chain. 
The choice of the optimal integration system will depend on the local circumstances as well as the objective of the system. If the main objective is to improve smallholder livelihoods, breeding cooperatives may be preferred over commercial companies, given that the general long-term goal of cooperatives is to maximize the welfare of their members companies aim to maximize their own profits. Specific efforts should be made in developing countries to implement breeding programs in parallel to fostering the marketing of products and breeding animals (Herold et al., 2012). In addition, breeding organizations should be developed considering culturespecific forms of organization (Herold et al., 2012), taking for instance into account local ethnical and gender issues.

\section{Choosing a given strategy}

The use of exotic AnGRs should be considered only if there is evidence that such introduction will increase animal performance by more than the arbitrary threshold of $30 \%$, in order to take into account multiple risks and challenges involved (FAO, 2010b).

Choice of the appropriate strategy will have a critical influence on the sustainability of any crossbreeding program. Three principal factors influencing the success of crossbreeding have been discussed earlier. Among these three factors, the ability of improved stock to express their genetic potential (environment control and constraints) and access to breeding stock are particularly critical for the choice of the strategy (Figure 3). Indeed the first factor influences the necessity to maintain genes from the local population (allowing the population to maintain fitness and survival in the local environment), whereas the second factor impacts the capacity of the smallholders to control the genetic composition of their animals. If local breeds do not possess traits of any interest for farmers (typically in industrial systems with no major environmental or feeding constraints), complete or nearly complete substitution with an improved breed will appear as the logical strategy for increasing production and farmer income. In cases where local breeds possess traits of interest, the choice of the strategy will depend of the factors described in Figure 3. Typically, harsher environmental conditions will demand maintaining a large proportion of indigenous genes within the cross (Burrow, 2006), whereas facilitated access to improved stock will favor the choice of terminal cross (for benefiting from heterosis) over synthetic breed creation. The cost of female replacements will be a

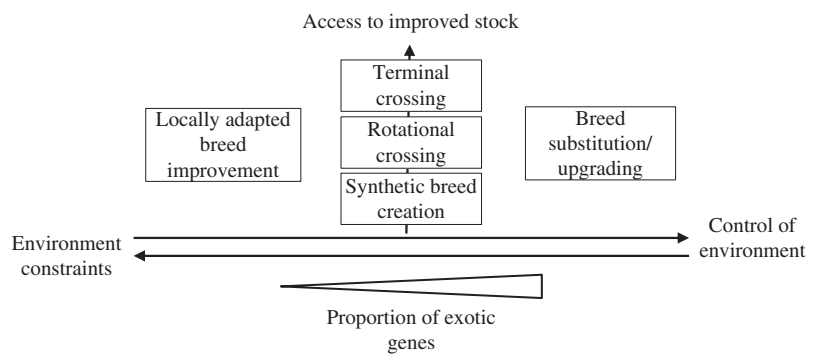

Figure 3 Schematic representation of choices of breeding strategies as a function of environment and access to improved stock constraints. determining factor for choosing rotational crossing over a terminal system. Although the level of integration within the market chain is less directly important for the choice of a given strategy, the fact that integration usually improves access to breeding stock and other inputs is expected to facilitate the implementation of crossbreeding programs requiring such access (i.e. rotational and terminal crossing, breed substitution).

Crossbreeding as a catalyst of innovation and development Several studies have investigated how different technologies and innovations are adopted (or not) by smallholders, including the use of crossbred animals (Abdulai and Huffman, 2005; Mekonnen et al., 2010). Use of crossbreeding is generally associated with adoption of other technologies (Al, vaccination, improved feeding and record keeping), as crossbred animals require greater care and improved management to achieve their full genetic potential.

For instance, in the survey by Abdulai and Huffman (2005), Tanzanian cattle farmers used credit for purchasing crossbred animals but also improved feeds, veterinary inputs or barns. The implementation of those technologies is positively associated to improved production, independent of the genotype (crossbred or indigenous) of animal raised (Ayalew, 2000; Mekonnen et al., 2010). The examples of dairy goat development projects in Ethiopia and Malawi are particularly interesting in that respect (Ayalew et al., 2003), because although the smallholders did not adopt crossbred animals at the end of the project, some associated innovations in husbandry practices were still maintained, allowing a significant increase of net benefits on the farms. Introduction of crossbreeding and its related technologies can therefore be considered as a catalyst allowing smallholders to be aware of and adopt other innovations, improving their livelihood in the long run, assuming these innovations are profitable.

\section{Conclusions}

Developing countries often rely on crossbreeding to improve performance of livestock populations (Figure 1), usually because they have not been able to implement proper genetic evaluation and straight breeding programs in locally available breeds has not been considered feasible. The failure to develop such breeding programs has been found to be related to poor infrastructure, insufficient capacity for management, lack of long-term commitment of research and investment, governmental and development institutes, and low involvement of smallholders in the implementation of the programs (Gizaw et al., 2014; FAO, 2015). Although crossbreeding allows countries to easily import the potential for rapid genetic progress, the sustainability of crossbreeding strategies usually depends on many of the same institutional factors as straight breeding. In addition, as suggested by the stagnant dairy performance and average milk yields over the recent decades in East Africa, crossbreeding needs to be continuous to maintain achieved performance levels in the 
absence of breeding programs, especially if attrition or natural selection against performance traits is taken into account. If adequate infrastructure, organization and support are not secured in the long run, thus ensuring regular provision of breeding stock, access to other inputs and integration within a proper value chain, the outcome of crossbreeding projects are likely to be instances of unmanaged introgression, threatening local genetic resources.

Climate change is foreseen to affect livestock through a combination of environmental challenges (e.g. increased heat and drought, reduced feed resources, more epidemics) and socio-economic factors (e.g. landscape use, shift in species, mitigation measures) (Pilling and Hoffmann, 2011). In many regions of the world, climate change will likely exacerbate the need for animals to have the resilience and other fitness capacities to deal with environmental stress that tend to be possessed by indigenous breeds (Hoffmann, 2013), as well as the production efficiency for low environment footprints usually possessed by exotic improved breeds. An appropriate combination of crossbreeding and selection (including genomic selection) may allow the exploitation of the capacities of both types of populations (Aby and Meuwissen, 2014). However, in developing countries, pedigree and performance recording remain a bottleneck for the implementation of selection schemes (Marshall et al., 2011). More generally, genomics provides effective tools to assess and monitor the level of introgression within local population (Leroy et al., 2012; Murray et al., 2013). Genome-wide analysis of crossbred and improved livestock under tropical conditions may also reveal the genomic regions submitted to recent selection and therefore linked to adaptation, as investigated by Kim and Rothschild (2014) in Kenyan dairy cattle. There is however a need for practical research to better characterize those traits and include them into breeding programs adapted to extensive conditions.

Crossbreeding adoption can be considered as part of an overall migration from a low-input/low-output system to a high-input/high-output system (Roschinsky et al., 2015). Under favorable conditions, crossbreeding schemes can be considered an effective strategy to reduce poverty among smallholders, through the increased animal performance and farmer benefits, to improve environmental efficiency, and as a trigger for innovation and development at the farm level. It can, however, not be recommended in extensive production systems unable to provide the necessary inputs. More than anything, the sustainability of a crossbreeding strategy requires a careful planning and long-term organization.

\section{Acknowledgment}

The authors would like to thank the French government for the secondment of Dr Gregoire Leroy to FAO.

\section{Disclaimer}

The views expressed in this publication are those of the author(s) and do not necessarily reflect the views or policies of the Food and Agriculture Organization of the United Nations. Also the designations employed and the presentation of material in this information product do not imply the expression of opinion whatsoever on the part of the Food and Agriculture Organization of the United Nations concerning the legal status of any country, territory, city or area or of its authorities, or concerning the delimitation of its frontiers or boundaries. Content and errors are exclusively the responsibility of the author.

\section{Supplementary material}

To view supplementary material for this article, please visit http://dx.doi.org/10.1017/S175173111500213X

\section{References}

Abdulai A and Huffman WE 2005. The diffusion of new agricultural technologies: the case of crossbred-cow technology in Tanzania. American Journal of Agricultural Economics 87, 645-659.

Aby BA and Meuwissen T 2014. Selection strategies utilizing genetic resources to adapt livestock to climate change. Proceedings of the 10th World Congress of Genetics Applied to Livestock Production, Vancouver, Canada, August 17-22.

Ahuja V, Dhawan M, Punjabi M and Maarse L 2008. Poultry based livelihoods of rural poor: case of Kuroiler in West Bengal. South Asia Pro Poor Livestock Policy Program. Retrieved February 6, 2015, from http://sapplpp.org/files-repository/ goodpractices/Report_Kuroiler\%20Study\%20Report_Final.pdf/at_download/file.

Ayalew W 2000. Do smallholder farmers benefit more from crossbred (Somali $\times$ Anglo-Nubian) than from indigenous goats? PhD thesis, GeorgAugust University of Göttingen, Göttingen, Germany.

Ayalew W, Rischkowsky B, King JM and Bruns E 2003. Crossbreds did not generate more net benefits than indigenous goats in Ethiopian smallholdings. Agricultural Systems 76, 1137-1156.

Bebe BO, Udo HMJ, Rowlands GJ and Thorpe W 2003. Smallholder dairy systems in the Kenya highlands: breed preferences and breeding practices. Livestock Production Science 82, 117-127.

Burrow HW 2006. Utilization of diverse breed resources for tropical beef production. Proceedings of the 8th World Congress on Genetics Applied to Livestock Production, Belo Horizonte, Brasil, August 13-18.

Central Bureau of Statistics (CBS) 2013. National sample census of agriculture, Nepal, 2011/12. Government of Nepal, Kathmandu, Nepal.

Food and Agriculture Organization of the United Nations (FAO) 2005. The legal framework for the management of animal genetic resources. FAO, Rome, Italy. Food and Agriculture Organization of the United Nations (FAO) 2007. Methods for economic valuation. In The State of the World's Animal Genetic Resources for Food and Agriculture (ed. B Richkowsky and D Pilling), pp. 429-440. FAO Commission on Genetic Resources for Food and Agriculture Assessments, Rome, Italy.

Food and Agriculture Organization of the United Nations (FAO) 2010a. Chicken genetic resources used in smallholder production systems and opportunities for their development. FAO Smallholder Poultry Production Paper No 5 (ed. P Sørensen). FAO, Rome, Italy.

Food and Agriculture Organization of the United Nations (FAO) 2010b. Breeding strategies for sustainable management of animal genetic resources. FAO Animal Production and Health Guidelines No 3. FAO, Rome, Italy.

Food and Agriculture Organization of the United Nations (FAO) 2011. Dairy development in Kenya. FAO, Rome, Italy.

Food and Agriculture Organization of the United Nations (FAO) 2012. Livestock sector development, economic growth and poverty reduction. In Livestock sector development for poverty reduction: an economic and policy perspective - livestock's many virtues (ed. J Otte, A Costales, J Dijkman, U Pica-Ciamarra, T Robinson, V Ahuja, C Ly and D Roland-Holst), pp. 57-75. FAO, Rome, Italy.

Food and Agriculture Organization of the United Nations (FAO) 2014. Ecosystem services provided by livestock species and breeds, with special consideration of small-scale livestock keepers and pastoralists. CGRFA Background Study Paper No. 66 rev.1 (ed. I Hoffmann, T From and D Boerma). FAO, Rome, Italy, 158pp. 
Food and Agriculture Organization of the United Nations (FAO) 2015. 2nd State of the World's Animal Genetic Resources for Food and Agriculture (ed. BD Scherf and D Pilling). FAO Commission on Genetic Resources for Food and Agriculture Assessments, Rome, Italy.

FAO, IDF and IFCN 2014. World mapping of animal feeding systems in the dairy sector. FAO, Rome, Italy.

Galukande E, Mulindwa H, Wurzinger M, Roschinsky R, Mwai AO and Sölkner J 2013. Crossbreeding cattle for milk production in the tropics: achievements, challenges and opportunities. Animal Genetic Resources 52, 111-125.

Gizaw S, Rischkowsky B, Valle-Zarate A, Haile A, van Arendonk JAM, Mwai AO and Dessie T 2014. Breeding programs for smallholder sheep farming systems: I. Evaluation of alternative designs of breeding schemes. Journal of Animal Breeding and Genetics 131, 341-349.

Gol/MoA 1997. 16th livestock census-2012 All India report. Government of India. Retrieved February 6, 2015, from http://dahd.nic.in/dahd/16th-indianlivestock-census-all-india-summary-report.aspx

Gol/MoA 2012. 19th livestock census-2012 All India report. Government of India. Retrieved February 6, 2015, from http://dahd.nic.in/dahd/statistics/livestockcensus/19th-indian-livestock-census.aspx

Hassen Y, Sölkner J, Gizaw S and Baumung R 2002. Performance of crossbred and indigenous sheep under village conditions in the cool highlands of centralnorthern Ethiopia: growth, birth and body weights. Small Ruminant Research 43, 195-202.

Havenstein GB, Ferket PR and Qureshi MA 2003. Carcass composition and yield of 1957 versus 2001 broilers when fed representative 1957 and 2001 broiler diets. Poultry Science 82, 1509-1518.

Herold P, Roessler R, Valle Zarate AV and Momm H 2012. Development of organisation and planning in animal breeding: I. A review on breeding organisation. Archiv Tierzucht 55, 402-414.

Herold P, Roessler R, William A, Momm H and Valle Zarate A 2010. Breeding and supply chain systems incorporating local pig breeds for small-scale pig producers in Northwest Vietnam. Livestock Science 129, 63-72.

Hoffmann I 2009. The global plan of action for animal genetic resources and the conservation of poultry genetic resources. World's Poultry Science Journal 65 , 286-297.

Hoffmann I 2013. Adaptation to climate change - exploring the potential of locally adapted breeds. Animal 7, 346-362.

Instituto Nacional de Estadistica e Informatica (INEI) 2012. IV censo nacional agropecuario 2012. Instituto Nacional de Estadistica e Informatica, Lima, Peru.

Kahi AK, Kosgey IS, Cardoso VL and Van Arendonk JAM 1998. Influence of production circumstance and economic evaluation criteria on economic comparison of breeds and breed crosses. Journal of Dairy Science 81, 2271-2279.

Kardivel G, Kumaresan A, Das A, Bujarbaruah KM, Venkatasubramanian V and Ngachan SV 2013. Artificial insemination of pigs reared under smallholder production system in northeastern India: success rate, genetic improvement, and monetary benefit. Tropical Animal Health and Production 45, 679-686.

Karugia JT, Mwai OA, Kaitho R, Drucker AG, Wollny CBA and Rege JEO 2001. Economic analysis of crossbreeding programmes in sub-Saharan Africa: a conceptual framework and Kenyan case study. Animal Genetics Resources Research 2. ILRI, Nairobi, Kenya.

Kim ES and Rothschild MF 2014. Genomic adaptation of admixed dairy cattle in East Africa. Frontiers in Genetics 5, 443.

Kocho T, Abebe G, Tegegne $G$ and Gebremedhin B 2011. Marketing value-chain of smallholder sheep and goats in crop-livestock mixed farming system of Alaba, Southern Ethiopia. Small Ruminant Research 96, 101-105.

Lapar MLA, Luan NN, Jabbar M, Figuié M, Quang HV, Moustier P, Binh VT and Steve $S 2010$. Estimating willingness to pay for quality and safety attributes of pork: some empirical evidence from northern Vietnam. In Demand for livestock products in developing countries with a focus on quality and safety attributes: evidence from Asia and Africa. Research Report No 24. (ed. MA Jabbar, D Baker and ML Fadiga), pp. 138-159. ILRI, Nairobi, Kenya.

Lemke U, Kaufmann B, Thuy LT, Emrich K and Valle Zárate A 2007. Evaluation of biological and economic efficiency of smallholder pig production systems in North Vietnam. Tropical Animal Health and Production 39, 237-254.

Leroy G, Kayang BB, Youssao IAK, Yapi-Gnaore CV, Osie-Amponsah RO, Loukou NE, Fotsa JC, Benabdeljelil K, Bed'hom B, Tixier-Boichard M and Rognon X 2012. Gene diversity, agroecological structure and introgression patterns among village chicken populations across North, West and Central Africa. BMC Genetics $13,34$.
Madalena FE, Agyemang K, Cardellino RC and Jain GL 2002. Genetic improvement in medium- to low-input systems of animal production, experience to date. Proceedings of the 7th World Congress on Genetics Applied to Livestock Production, Montpellier, France, August 19-23, 25 (08).

Madalena FE, Peixoto MGCD and Gibson J 2012. Dairy cattle genetics and its applications in Brazil. Livestock Research for Rural Development 24, 97.

Makoni N, Mwai R, Redda R, van der Zijpp A and van der Lee J 2013. White gold opportunities for Dairy Sector Development Collaboration in East Africa. Centre for Development Innovation, Wageningen, The Netherland.

Marshall K, Quiros-Campos C, Van der Werf JHJ and Kinghorn B 2011. Markerbased selection within smallholder production systems in developing countries. Livestock Science 136, 45-54.

Mbole-Kariuki MN, Sonstegard T, Orth A, Thumbi SM, Bronsvoort BMC, Kiara H, Toye P, Conradie I, Jennings A, Coetzer K, Woolhouse MEJ, Hanotte 0 and Tapio M 2014. Genome-wide analysis reveals the ancient and recent admixture history of East African Shorthorn Zebu from Western Kenya. Heredity 113, 297-305.

Mekonnen H, Dehninet G and Kelay B 2010. Dairy technology adoption in smallholder farms in Dejen district, Ethiopia. Tropical Animal Health and Production 42, 209-216.

Miazi OF, Hossain E and Hassan MM 2007. Productive and reproductive performance of crossbred and indigenous dairy cows under rural conditions in Comilla, Bangladesh. University Journal of Zoology, Rajshahi University $26,67-70$.

Minister of State for Planning (MSP) 2009. 2009 population \& housing census results. Kenya census 2009. Minister of State for Planning, Nairobi, Kenya.

Muriuki HG and Thorpe W 2002. Smallholder dairy production and marketing in eastern and southern Africa: regional synthesis. In smallholder dairy production and marketing - opportunities and constraints. Proceedings of a South-South workshop held at NDDB, Anand, India, March 13-16, 2001, pp. $185-200$.

Murray GGR, Woolhouse MEJ, Tapio M, Mbole-Kariuki MN, Sonstegard TS, Thumbi SA, Jennings AE, van Wyk IC, Chase-Topping $M$, Kiara $H$, Toye $P$, Coetzer K, Bronsvort BMC and Hanotte 0 2013. Genetic susceptibility to infectious disease in East African Shorthorn Zebu: a genome-wide analysis of the effect of heterozygosity and exotic introgression. BMC Evolutionary Biology $13,246$.

Nath BG, Pathak PK, Ngachan SV, Tripathi AK and Mohanty AK 2013. Characterization of smallholder pig production system: productive and reproductive performances of local and crossbred pigs in Sikkim Himalayan region. Tropical Animal Health and Production 45, 1513-1518.

Otieno DJ 2013. Market and non-market factors influencing farmers' adoption of improved beef cattle in arid and semi-arid areas of Kenya. Journal of Agricultural Science 5, 32-43.

Pattison J, Drucker AG and Anderson S 2007. The cost of conserving livestock diversity? Incentive measures and conservation options for maintaining indigenous Pelón pigs in Yucatan, Mexico. Tropical Animal Health and Production 39, 339-353.

Peacock C, Ahuya CO, Ojango JMK and Okeyo AM 2011. Practical crossbreeding for improved livelihoods in developing countries: the FARM Africa goat project. Livestock Science 136, 38-44.

Pilling D and Hoffmann I 2011. Climate change and animal genetic resources for food and agriculture: state of knowledge, risks and opportunities. Background Study Paper 53. FAO, Rome, Italy, 45pp.

Quddus MA 2012. Adoption of dairy farming technologies by small farm holders: practices and constraints. Bangladesh Journal of Animal Science 41, 124-135.

Rege JEO, Marshall K, Notenbaert A, Ojango JMK and Okeyo AM 2011. Pro-poor animal improvement and breeding - what can science do? Livestock Science $136,15-28$.

Roschinsky R, Kluszczynska M, Sölkner J, Puskur R and Wurzinger M 2015. Smallholder experiences with dairy cattle crossbreeding in the tropics: from introduction to impact. Animal 9, 150-157.

Steglich M and Peters KJ 2003. Participatory methods to assess traditional breeding systems: the case of cattle breeding in the Gambia. In Conservation and sustainable use of agricultural biodiversity: a sourcebook (ed. D Campilan, J Rivaca-Caminade, H de Ckhavez, P Eyzaguirre, J Gonsalves, W Pelegrina, R Vernooym and A Von Lossau), pp. 123-132. CIP-Upward, Manila.

Widi TSM 2015. Mapping the impact of crossbreeding in smallholder cattle systems in Indonesia. PhD thesis, Wageningen University, Wageningen, 136pp. 